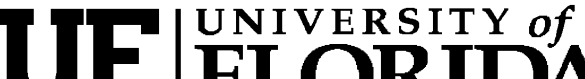 FLORIDA \\ IFAS Extension
}

\section{How to Write for Your Website ${ }^{1}$}

\section{Sarah Graddy and Tracy Irani ${ }^{2}$ \\ Introduction}

Websites are an easy and increasingly important way for Extension to reach its audience, and focus groups working with UF/IFAS on the Solutions for Your Life project have indicated that many Floridians consider the Internet their primary source of information.

According to the Pew Internet \& American Life Project, $73 \%$ of adult Americans surveyed in late 2005 and early 2006 said they use the Internet - and the younger the person, the more likely it is that he or she is online.

We need to take advantage of these facts to ensure that our users get the information they seek. The way we write content for our Web pages will determine whether we succeed.

How do you write for your Web page? Writing for the Web is pretty straightforward, but it is different from other kinds of writing.

\section{Reading Online}

Visitors scan, rather than read, Web pages. When they do read content online, they read at a rate 20-30\% slower than they read words on the printed page.

Readers look for keywords relevant to their search and don't typically slow down to read long, wordy text. There is no exact formula for the right amount of text to post on a website, but the rest of this article will give specific tips on how to make your writing easier to read.

\section{What to Post}

Many people think that once a website is created, their task is done. In fact, the work of making a website useful and easy to use is never done.

Revisit old items periodically (every few months, or more often if possible) to see if content is still relevant, if you can add information, or if you need to make any changes. This includes your own contact information! If your website has broken links or content that is obviously out of date (an article dated more than just a couple of years previous, or a

1. This document is AEC-378, one of a series of the Agricultural Education and Communication Department, Florida Cooperative Extension Service, Institute of Food and Agricultural Sciences, University of Florida. Original publication date August 2006. Visit the EDIS website at http://edis.ifas.ufl.edu.

2. Sarah Graddy; writer and content developer, Center for Landscape Ecology and Conservation; Tracy Irani, associate professor, Department of Agricultural Education and Communication; Florida Cooperative Extension Service, Institute of Food and Agricultural Sciences, University of Florida, Gainesville, FL. The use of trade names in this publication is solely for the purpose of providing specific information. UF/IFAS does not guarantee or warranty the products named, and references to them in this publication does not signify our approval to the exclusion of other products of suitable composition.

The Institute of Food and Agricultural Sciences (IFAS) is an Equal Opportunity Institution authorized to provide research, educational information and other services only to individuals and institutions that function with non-discrimination with respect to race, creed, color, religion, age, disability, sex, sexual orientation, marital status, national origin, political opinions or affiliations. U.S. Department of Agriculture, Cooperative Extension Service, University of Florida, IFAS, Florida A. \& M. University Cooperative Extension Program, and Boards of County Commissioners Cooperating. Larry Arrington, Dean 
copyright on the bottom of the page from any year other than the current one), you will lose your visitors' trust and attention. Disgruntled visitors will leave your site, maybe never to return.

Make sure your content is timely. Change featured items according to season, or to highlight special events. Visitors who repeatedly go to a site that never changes will eventually figure out that there will not be any new information for them and will stop going to that site.

Use link-checking software as often as you can-at least once a month, but preferably closer to once a week. You can get this software free online (e.g., Xenu's Link Sleuth ${ }^{\mathrm{TM}}$ ). This program can run in the background while you do other things, and it will generate a report that tells you where all of the broken links are on your site.

User statistics will tell you a lot about how people are getting to your site and how they are using it; you'll want to consult these statistics frequently so that you can adapt your content to reach more people. You can find out, for example, what keywords people type into Google and other search engines to get to your site. You might be surprised by what you learn. This information can help you when you re-evaluate your content. Do your headings contain the words used in searches? They should!

\section{Language}

The Web is informal. It is acceptable-and in the case of Extension writing, probably preferable - to use the second-person pronoun, you, when referring to the reader. Instead of Lovebugs should be removed from cars with water within twenty minutes, try Wash your car with water within twenty minutes. It's more active and has immediate relevance to the reader.

Titles should grab the eye. They should be catchy but not coy, as clear and short as possible, and accurate, with a minimum of technical language. Instead of calling your article "Plants out of Place" (cute and non-descriptive) or "Getting Rid of Nonnative and Exotic Plants in Residential Lawns" (dull, intimidating, and not reader-centered), call it "Invasive Plants: What You Can Do."
Get to the point right away. Start with what you would normally consider the "conclusion." This tells your readers what's in it for them.

Avoid jargon. Of course, acronyms are sometimes unavoidable, and in those instances you'll want to spell out each acronym (or initialism) the first time you use it, parenthetically inserting the shorter version. Example: For more information, you can call the Department of Agriculture and Consumer Services (FDACS). After that, you can just refer to $F D A C S$. If you expect your audience to be made up of professionals (as opposed to members of the general public), you can probably get away with a bit more jargon.

Use the active voice. Try to use action verbs instead of passive verbs like is, has, and does. Write Check your lawn for invasive plants, not The lawn should be checked for invasive plants. Write short, straightforward sentences. Shorten everything you write: write your copy, then cut all unnecessary words. This will make your writing more interesting and easier to read.

Try to use as many keywords related to your topic as possible to guide readers to you from search engines and help them find the information they need within your text. For example, instead of referring to turf throughout a page, you may want to sometimes substitute the word grass, since that is probably a more commonly used search term. Google's AdWords

(

http://adwords.google.com/select/

KeywordToolExternal) and Overtures Keyword Selector Tool (http://advertising.yahoo.com/smallbusiness/ysm) will generate keywords and show you search statistics for them.

\section{Format}

Try to avoid posting text that requires a great deal of scrolling. On the other hand, don't shorten the text so much that it loses its usefulness to the reader.

Readers find it hard to follow text across the screen, so the number of characters per line on your Web page should be fewer than in a paper text-that 
is, columns should be narrower. There is no universal standard for width, but most usability experts recommend between 40 and 60 characters (66 is usually recommended for print).

Use headings to separate sections if you can. Headings break up the text for readers and allow them to find keywords while scanning text. A good way to break up text longer than a few paragraphs is to create a menu at the top of the page that indicates the sections found in the text (this works only if the sections have headings). Then readers can look at the menu before reading any of the text and go straight to any sections that appeal to them.

Again, use short sentences. Stick to one idea per paragraph. Paragraphs on a Web page should be shorter than they would be on paper. It isnt unusual or wrong on a Web page to have a paragraph made up of only one or two sentences.

Use bullets when you can to break up information. Lists work very well online.

In general, try to incorporate as much white space as possible into your text to give readers' eyes a break.

Although you'll want to link to other pages from your site, avoid having more than a few links within body text. Rampant linking in paragraphs is visually disruptive, drawing your reader's eyes to the links at the expense of the surrounding text, which probably wont get read before the reader begins clicking on links. Instead, put links to related resources in a separate place (see Organization, below).

If you must emphasize something in your text, use italics. Underlining on the Web should be reserved for links only. Bold text is hard to read and, again, visually disruptive.

\section{Organization}

Of course, you will probably want to give your readers links to publications and other websites - after all, connectivity is what the web is all about. Links to other pages, especially those outside your site, should be reserved for a specific area of your site, preferably the right side, or at the end of your content. (Consider having a "See also" or "For more information" section on pages.) Group these in a systematic way-instead of just having a list of random links, consider alphabetizing them. Or, if you have more than about six links, see if you can subdivide them into two or more sections grouped by theme. These simple steps make links more meaningful and less confusing to users skimming rapidly for relevant and useful information.

\section{Editing}

Spell-check, re-read, and edit everything you write before you post it online. Ask someone-preferably a good editor-to look over material before you post it to make sure you've presented the material clearly and have caught all errors. After you post your content, read it again online to make sure you didn't miss anything.

Use a style guide to make sure your writing is consistent. The Chicago Manual of Style (CMS) is a popular and useful guide to follow. The IFAS Web team has also put together a Web style guide, based on CMS, that highlights items particular to IFAS, as well as common Web writing errors. It is posted online at http://solutionsforyourlife.ufl.edu/customer_service/ files/SFYL_Web_Writing_Style_Guide.pdf

\section{Exceptions/Corollaries}

There are, of course, exceptions or corollaries to everything you've just read.

First of all, you want to be user-friendly, but not at the expense of useful content. Don't shorten things so much that readers feel let down - they came all this way for this? Don't "dumb-down" your materials-just make them easy to read!

Remember that many visitors will be coming to you with specific questions, so they might be willing to read a lot to get the information they need-if the writing is good, and the material is broken up so that it is easy to navigate and skim. Many readers will print out longer articles to read or refer to later, so having substantial content that they can actually use is important. It's often a good idea to let your readers self-select whether they want more content-in other words, to give a shortened version, with the option for 
those who want more information to go deeper into the content by going to another page.

\section{Summary}

Writing for the Web is becoming increasingly important in Extension and calls attention to the ways in which we need to change our approach to disseminating information. Many users are accessing Extension materials online, and some of them may not even know what Extension is.

Our audience is larger and more diverse than ever. When writing, we should be aware that many people will access our materials without ever making contact with an agent who could interpret, expand on, or explain our content. We must be clear and to-the-point with our writing to reach our Internet audience.

Finally, we must evaluate our audience and its needs before we post content.

\section{Useful Sites}

- AdWords-Google http://adwords.google.com/select/

KeywordToolExternal (accessed August 3, 2006).

- Keyword Selector Tool-Overture http://advertising.yahoo.com/smallbusiness/ysm (accessed August 3, 2006).

- Pew Internet and American Life Project http://www.pewinternet.org/ (accessed August 3, 2006).

- Research-based Web Design and Usability Guidelines http://www.usability.gov/guidelines/ (accessed August 3, 2006).

- Solutions for Your Life Web Style Guide http://solutionsforyourlife.ufl.edu/ customer_service/files/ SFYL_Web_Writing_Style_Guide.pdf (120KB pdf) (accessed August 3, 2006).

- Usability Guides and Checklists-U.S. Department of Health and Human Services http://www.usability.gov (accessed August 3, 2006).
- Web Style Guide http://www.webstyleguide.com/index.html (accessed August 3, 2006).

- Writing for the Web_-Jakob Nielsen http://www.useit.com/papers/webwriting/ (accessed August 3, 2006). 